\title{
PENSANDO A ESCOLA... POR CAMINHOS E POTENCIALIDADES
}

Iniciamos essa edição com o artigo encomendado que aborda currículo, arte-educação e cultura visual. De autoria de Gianne Maria Montedônio Chagastelles e de Christiane de Faria Pereira Arcuri, esse artigo traz para o debate os estudos da cultura visual na contemporaneidade, sendo este um parâmetro para a atualização de conteúdos curriculares relacionados ao ensino de artes na escola e à alfabetização estética. Temas tão atuais e necessários nos contextos escolares do século XXI. Erinaldo Ferreira e Soênia Maria Pacheco debatem as relações existentes entre o espaço físico escolar e a avaliação externa do desempenho, propondo a reflexão sobre a participação dos estudantes na escola e sobre o desempenho escolar por meio de testes padronizados. A lateralidade e o fracasso escolar são discutidos por José Antônio Vianna, ao considerar as restrições motoras de crianças em idade escolar e os modos de vida presentes na sociedade atual; eis uma rica contribuição para os que transitam cotidianamente nos espaços escolares, lidando com as diferenças e com as demandas apresentadas por essas diferenças. Em uma linha muito próxima, o artigo de Ângela Fernandes de Melo também considera a diferença pelo viés da inclusão do aluno com síndrome de down na educação básica. A autora nos convida à reflexão a partir da compreensão dos desafios enfrentados na inclusão do aluno portador de Síndrome de Down dentro do contexto da educação básica e da inclusão em classe regular, relacionando ao papel do professor e aos procedimentos pedagógicos sob o ponto de vista teórico. A sessão Resenhas, apresenta o livro "Estrutura de classe e mobilidade social no Brasil", de autoria de Carlos Antônio da Costa Ribeiro, pelas mãos de Wallace Ferreira, trazendo uma contribuição sobre a desigualdade social brasileira no século XXI.

Desejamos, mais uma vez, boa leitura a todos/as!

Andrea da Paixão Fernandes 